resultaten der vel'schillende conecrn onderdeclen. Immers hoc gemiakelijk komt ecn oppervlakkig beschouwer er niet toe to zegigen, dat bedrijfsonderdeden, die voortdurend met nadeelige resultaten werken, moeten worden geliquideced. Doch hierbij wordt dan vergeter. wat de invloed is op de overige bedrijfsdeclen, tengevolge van zulk een godeeltelijlie opheffing. De vraag dicnt in zulk cen geval toch gesteld, om nu mal slechts dit te noemen: Hoeveel zullen de werkelijkc zelfkosten van het halffabrikat, tengevolge van mindere productie stijgen? Dit voorbeeld toont naar mijn meening duidelijk alan, dat de resultaten van elk onderdeel aftzonderlijk moeten worden beoordecld, hetgeen ecn raten te meer is, dat bij ecn geeonsolidecrle resultatemekening geen bant te vinden is.

Intien nu de v'adag zou worden gesteld: Is in een lreknopten rorm cen resultatenrekening van een Coneclneentrale samen te stellen, die cen inzicht in de hedrijfsresultaten geeft, dan zon het antwoord ongetwijfeld ontkennend moeten luiden. De beste oplossing lijkt mij nog deze, lat de werkelijke resultaten der verschillende Onderhoorige Ondermemingen afzonderlijk worden vermeld, alhoewel ik el mij ran bewst ben, dat ook hiertegen versehillende be\%aren kumen worden ingebracht. Zoo zal b.v. om commereiöcle redenen deze publicatievorm dikwijls minder gewenscht zijp.

3. Thans lest mij nog het aan het begin genoende punt 3 te hespreken.

Jetgeen ik reeds heb opgenerkt maakt het mij mogelịk mị bij re toolichting van dit punt beperking op te legrgen.

Ilet is mij bekend, dat do meeningen in vakklingen verdeeld zijp over het antwond op de ragag: , Ilerft de aceountant in het rappolt over do jaarrekening, naast modedeeling zijner hevindingen naar andeiding der verrichte controlewerkzaamheden. ook een cijferhooordecling to goven?"'

Youdel nu op het vone en tegen del hierover bestaande meeningen in to garan, zij vermeld, hat nal mijn opvatting de accountant wol cen cijferboordecling in zijn rapport heeft te geven. Ion is ecmmanl deze opvatting anvalard, dan is daamede togelijkertijd de noodzakelijkheid erkend, dat een gcconsolideerde balans der concern fintrale moet worden samengesteld, omdat zonder deze. de toestand ran het bedrijf ommogelijk kan worken beoordeeld. ITetgeen ik diktrumtrent mededeelde bewijst de noodwendigheirl darivan voldoende.

Wie hiepuif nu de conchusie zon willen trekken, alsof ik van mecning zou zijn, dat de aecountant de balans eener. Concem Centrale in den nuden vorm nict zou mogen onderteckenen, tast mis. Jk zic niet in, dat el cenig bezwar tegen gemaakt hohoeft te worden, de balans in har ouden vorm te onderteckenen. mits de juistheid der dan lop voorkomende gegevens natumlijls is vastgosteld. Wel acht ik het gewenscht. dat de areountant in de kopte aceountantsrepklaring zijn mecning zogt over de beide brangrijke posten: ,Aandeelen in en Voorschotten aan Onderhonrige Ondermemingen".

Doch roor intern docl $\mathrm{cm}$ vonl de eijferboordeeling is de geconsolidecede halans onmishan', hetgeen ik in het roorgaande meen te hebhen aangetoond.

Hierann voeg ik nog toe, dat ik mijj meermalen heb afgevraagd. hoe het komt, dat deze zere helangrijke materie, in de Iollandsche vakliteratum, althans voorzoover mij bekend, niet cerder een onderwerp van hespreking heeft uitgemaakt. Maal meer nog heb ik er mị over verwonderd hoe het te verklaren is, dat vele onzer Hoilandsche collegal's, zooals mij is gebleken, het belang van consolideeren ran balansen van groote concerns niet inzien. Mren spreckt van concerus met h.v. 20 dochterondernemingen, waarvan men alle balansen als toclichting bij de balans del Moedermij wil publiceeren. Hierbij is reeds het inzicht, wannecs de publicatie op deze wijze geschicdt, zeer mocilijk. Ioch zou men nu werkelijk denlien, dat het eijfermateriaal van de balans eencr Moedermij, met lat me zeggen de balansen van b.v. 200 aancresloten ondernemingen, nog eenige waarde heeft on zelfs een globalen indruk van den toestand van het concern te verkrijgen? Ik ben er van overtuigd, dat een accountant, aan wien ecn oordeel over een dergelijke onderneming zou worden gevragd. dit zonder consolidatie onmogelijk zou kunnen geven.

Een omwerking der Restultatenrekening in cen anderen vorm aclut ik nict noodig. omdat de verschillende onderdeclen toch afzonderlijk moeten worden bekeken, hetgeen ik voldoende meen te hebben toegelicht.

'Ten slotte meen ik nog te moeten opmerken, dat ik mij ten volle bewust ben, dat ik het onderwerp bij lange na niet in rijn vollen omvang heb behandeld. Doch dit is in een kort tijdsbestek ook niet mogelijk. Ik hel nit de voornaamste punten slechts hier en daar een greep kunnen doen.

\section{BESLECHTE GESCHILLEN}

Red. Mr. A. E. J. NYSINGH

(Bijdragen en mededeelingen zende men aan den Secretari; der Redactie)

\section{PIAATSING VAN KAPITAAI, ER KONINKLIJKE} BETTITIGTNG BIJ DE OPRICHTING VAVN NAAMLOOZE VENNOOTSCHAPPEN

Voos de opplichting vall een Namlooze Vennootschap is volgens de wet een notalpicele acte noodig, welke Koninklijk moet zijn goedgekenrd. d.w.z. de Koninklijke Bewilliging moet op die acte zelf of op hot ontwerp daarvan zijn verkregen.

Nu bevat het Wetboek van Koophandel twee bepalingen walrin gesproken wordt orer de plaatsing en storting van kapitaal in verband met de oprichting, de artikelen 50 en 51 .

Artikcl 50 ecrste lid luidt:

,We Koninklijke Bewilliging zal niet worden verleend, tenzij bijke dat de eerste oprigter's te zamen ten minste een vijfde van het maatscluppolijk kapitaal vertegenwoordigen".

Artikel 51 luidt:

De Vemootschap at haren adnvang niet kumen nemen, tcr ware ten minste tien ten honderd van het gemeenschappelijk kapitaal gestort zij".

()ver de beteekenis van deze bepalingon heeft de Hooge Ratad op 19 Juni 1925 cen arrest gewezen, dat de aandacht verdient.

Te ruator in het faillissement van cen Namilooze Vemnootschaj, cen assurantiemaatschappij, vorderde van cen aandeclhouder volstorting van zijin aandeclen.

Dergelijke vorderingen vallen bij do betrokkenen gewoonlijk niet in goede alarde.

Dat was hier clan ook het geval. Men hetaalt nu eenmaal niet glaag wamner vaststaat dat wat men betaalt, niet meer zal rendecren en zonder meer verloren is.

'T'egensputteren helpt echter niet wameer mon geen verweer' weet te voeren dat in rechte houvast gecft.

De bedoelde aandeelhomder meenthe een dergelijk verweer te hehben gevonden: de gefailleerde Namlooze Vemmootschap was wel opgericht hij notaricele acte, de Koninklijke Bewilliging was ook wel verleend, maar ...... noch bij de oprichting, noch bij zijn toetreding ils andeolhouder was cen vijfde gedeelte van het maatschappelijk kapitaal geplaatst geweest, terwijl toen 
al evenmin $10 \%$ van het Maatschappelijk kapitaal was gestort.

Wat zou daaruit nu moeten volgen?

Volgens den bewusten aandeelhouder heel veel.

In de eerste pliats, chit de Nanmlooze Vemnootschap niet bestaan heeft, dus nict kon worden failliet verklanrd; de curator was culator in ecn faillissement van iets dat niet bestaat en mist dus de bevocgdheid on als zoodanig op te treden; hij vertegenwoordigt niets, heeft niets te vereffenen. Hij mist dus de qualiteit, warin hij vordert; met zoo iemand heeft de aandeelhouder nict te maken.

In de tweede plaats, dat de toetreding, de verbintenis tot deelname van den aandeelhonder nietig zou zijn, omdat zij was aangegaan jegens een lichaam, dat niet rechtsgeldig, en in rechte dus niet bestond.

In de derde plats dat, ook al zou het bestaan moeten worden aangenomen, in ieder geval de vemootschap nog geen aanvang had kunnen nemen zoolang niet $10 \%$ van het geplaatste kapitaal gestort was en ook om deze reden dus nog geen overeenkomsten had kumnen sluiten of verbintenissen had kunnen angaan of aanvaarden.

Inderdaad stond in dit geval vast, lat de platsing van een vijfde gedeolte van het kapitaal on storting van $10 \%$, als bedoeld in de bovenaangelialde artikelen 50 en 51 van het Wetboek van Kooplandel, niet had plaats gehad, al was de Koninklijke Bewilliging wel verlecnd. Doch volgt nu uit die nietplaatsing, dat de rechter de Vemootschap als nietig, immers als niet-bestaand, moet aammerken?

Neen, besliste Rechtbank en Hof; artikel 50 stelt wel een eisch voor het verleenen van de Koninklijke Bewilliging, doch wamneer deze ecnmaal is verleend komt cen nader onderzoek nict te pas; met het verleenen van de Koninklijke Bewilliging is dit punt afgedaan.

Weliswaar, voegt het Hof hieraan toe, staat door het verleenen van de Koninklijke Bewilliging niet altijd vast, dat cen wettige Naamlooze Vemootschap is tot stand gekomen; dit mag niet worden aangenomen, wanneer een der wezenlijke elementen ontbreekt, bijv. wanneer van het kapitaal nicts was geplaatst; maar de vraag, of $\mathrm{er}^{\mathrm{r}}$ iets meer of minder dan juist een vijfde gedeelte van het kapitanl is geplaatst is van geen belang voor het wettig tot stand komen, indion de Koninklijke Bewilliging is verkregen.

Contrôle dus door den rechter als het de spuigaten nitloopt; maar in gevallen van twijfel is het woold aan de kroon, en heeft de rechter zich voor de door de Regeering verleende bewilliging te buigen.

Hoe het Hof dit stelsel uit de wet afleidt zogt het niet en blijft voor ons een raadsel. In de cassatie procedure, die op het arrest volgde, werd dit standpunt dan ook noch door" den Procureur Generaal, noch door den Hoogen Raad onderschreven, al verschillen ook deze onderling van meening.

De meening van den Procureur Generaal was kort en bondig deze: de plaatsing staat uitsluitend ter boordecling van de Regeering, die zelfstandig en zonder eenige contrổe onderzoekt of aan het vereisehte van artikel 50 is voldaan. "Antwoordt zij bevestigend dan mag geen rechter ter wereld haar besluit controlecren of ongedaan maken'". Terecht of ten onrechte verleend, indien de Koninklijke Bewilliging emmaal is afgekomen, bestaat de Vennootschap, en heeft ieder, ook de rechter, haar als zoodanig te cerbiedigen.

Men kan zich roos deze meening berocpen op de woorden van de wet, n.l. op dic van het hovenanngehaalde altikel 50, on missehicn ook op altikel 36 tweede lid:

"Alvorens de zelve tot stand kan worden gelbragt, moct de .acte harere oprigting, of en ontwerp datrvan, aan den lio,,ning worden ingezonden, ten einde daurop Zijne bewilliging ,.te erlangen"'.

ondat daaruit zou voortvlocien, clat, wanneer de Koninklijlise Bewilliging eenmaal is verlecend, de Vemootschap ook tot stand kan worden gebracht en dus tot stand lomt, har kracht ontlecnt zij aan de geschiedenis.

De Koninklijke Bewilliging is van F'janschen oorsprong en was in den Code de Commerce opgenomem, nadat Kieizer Napoleon te voren reeds order had gegeven ann zijn Minister van Bimenlandsche Zaken om hen rapport uit te brengen omtrent alle bestande Vemootschappen en de actes van oppichting an zijn goedkeuring te ondejwerpen, Sa Majesté étant frappée de l'inconvénient d'abandomner aux particuliers les sociétés anonymes."

De benoeiingen van het Gouvernement gingen veel verder dan enkele goedkeuring van de oprichtings acte; cl was vooltdurend toezicht en contrôle en mogelijkheid van intrekling der cens verleende goedkeuring door de Regeering.

De Nederlandsche Regeering hield in de ontwerpen, welke in 1826 en 1833 bij de Staten Generaal werden ingediend, aan deze regeling vast.

Aanvankelijk zonder verzet.

Totdat een adres aan de Staten Gencraal ,door onderscheiden aanzienlijke kooplieden ler hoofdstad geteekend" de zaak aan het jollen bracht.

Dat adres begon met er op te wijzen, dat de bepaling van Fransehen oor'sprong was en, in den geest eener Regecring, gelijk de fransche, die zich in alle burgerlijke betrekkingen als heerscheres wenschte te doen kennen, en waande, of scheen te wanen, dat bij haar en hare ambtenaren de kennis van alle soort van zaken en bedrijven berustte", doch in strijd, ,net onzen aard, onze zeden en ons handelsbelang'. Wn na craan herinnerd te hebben, dat de zaak in Frankrijk door bovenbedoeld decreet van Napoleon reeds beslist was vóór de wet zelve tot stand kwam gaat het adres voort: ,En wien, die den geest kent, welke het tijdvak der keizerlijke overheersehing kenmerkte, zal dan nict dit reeds doen bedachtzaam zijn? Wat wetgever val een Iaand, waar alleen vrij onderzoek geldt en gelden moet, zal nict het doelmatige ecner wetsbepaling wan1rouwen, onder zulke onstandigheden daargesteld?" Het adres betoogt dan verder, dat Koninklijk toezicht geen zin heeft en belemmerend op den handel workt, die aan zich zolf kan worden overgelaten; dat de amtbenaren ook niet in stat zijn een juist oordecl over de handelsondernemingen to vellen, en zeker een minder juisten hlik op den handel hebben dan de betrokkenen zelf, cn eindigt met een zinsuede, welke wij ons niet weerhouden kumnen in haar geheel op te nemen:

, , $\Lambda \mathrm{ls}$ Wetgevers van een Land, waar alle belemmering van handel en nijverheid, steeds, en zoo de ondergetcekenden meenen te regt, als verderfelijk voor 's Lands bloei en de welvaart der' ingezetenen beschouwd is, - war geene wuftheid, maar bedachtzaamheid, geen ligtzinnig wagen, maar cen zorgvuldig berekenen der waarschịnlijke uitkomsten elke onderneming regelt, - waar eindelijk kennis van al wat tot nijverheid of handel behoort, of dienen kan on dezelve op vaste grondslagen 
te vestigen, ook thans nog meer dan elder's huisvest, - zullen Ued. Mog., gelijk de ondergeteckenden cerbiedig vertrouwen. niet aarzelen, uit de Vaderlandsche Wetgeving een beaninsel to weren, dat, op vreemden grond ontkiemd, deszelfs overbicuging op onzen bodem alleen heeft gekenmerlit door het verwekken van wrevel en ongenoegen, dat reeds meel dan érns den handolgeest heeft gestremd, en watrvan de noodzakelijkheid of doelmatigheid in ons Vaderland nimmer" crgens anders, dan wellicht in de burcaux der adninistratie, is erkend geworden".

De Regecring was in haal wiek geschoten; zij diende ecn nadere memoric ter weerlegging ran het adres bij de Staten Generaal in, waalin zij begron met op te merken, dat zij het verzet niet goed begreep, ondat het ontwerp 1826 met algemeene stemmen in de Kamer was anngenomen eu hij niemand op verzet had gestuit, ook niet bij de Kamers van Koophandel ran Ansterdam, Antwerpen en Rotterdam, welke over het ontwerp waren geraadpleced; ,waaruit voorzeker met het hoogste regt mag en moet worden afgeleid, dat de bezwaren, welke alsnu tegen dien heilzamen en onontbecrlijken matregel worden ter bane gebragt, toch niet zecr wezenlijk zijn, daar dezelve anderszins niet aan het doorzigt en de schranclerheid van zoo vole in het vak van koophandel doorkundige en crvaren mannen zouden zijn ontelipt".

Op deze opmerking volgt dan verder een lang betoog walarvan de kern dit is: de Naamlooze Vennootschap vormt ecn uitzondering op het gewone rechtbeginsel, dat ieder aansprakelijk is met zijn geheele vermogen voor aangegane verbintenissen; het is cen voorrecht, dat de declhebbers slechts met het bedrag van hun deelname aansprakelijk zijn. Bị het scheppen van een dergelijke bevoorrechte positic zijn waarborgen noodig tegen misbruiken; waarborgen, dat de vennootschap zich nict zal richten tegen het algemeen belang; waarborgen, voor de deelnemers, dat zij niet onder schoone voorspiegelingen in nictreëele ondernemingen zullen worden gesleept; waarborgen voor derden, dat zij met een reciele onderneming te doen hebben. Dic warborgen liggen in let toczicht van de Regecring. ,Men heeft een oogenblik in beraad gestaan, of ook, met ter zijde stelling van het toczigt der Hooge Regeering (hetwelk Zij voorwaar niet onder IIare aangenaanste bemoeijenissen telt), bij de wet zelve zekcre regclen omtrent de statuten der naamlooze maatschappijen zouden kumnen worden voorgeschreven; doch men heeft dat denkbecla, in het belang dier matschappijen, laten varen, ondat sehier niemand het zoude durven wagen zoodanige venmootschappen op te rigten en daaraan deel te nemen, indien het van de opvatting des regters afhing te beslissen, of bij de statuten die voorschriften al dan nict zijn nagelecfd, - waarvan het gevolg zoude zijn, dat, bij eene ontkennende oplossing, zoodanige vemmootschap het karakter van naamloosheid missende, de vennooten solidaiv zouden aansprakelijk zijn; - telwijl in het aangenomen beginsel, dat die goedkeuring door den Koning moet verleend worden, ja zelfs. in geval eener mogelijke opgevolgde Koninklijke intrekking dier goedkeuring, - de bestuurders en declgenooten steeds tegen alle aansprakelijkheid zijn gredekt, indien slechts de acte. de statuten on het Koninklijk [Besluit op de wijze bij de wet voorgeschreven, zijn openbaar gemaakt".

De Regeering heeft haar tegenstander's nict overtuigd; verschillende kamerleden hleven bezwaren opperen; de regeering deed concessies, 0.a. zag zij af ran het repressief toezicht (art. 37 lid 3 ,Geene door den Koning bewilligde naimlooze vennootschap, wordt door hem ontbonden, ter zake dat de bestuurders aan de bepalingen en voorwaarden der alste niet hebben voldaan") op grond dat door de bepaling van artikel 45 lid 2, welke de bestuurder's persom] ijk aansprakelijk doct zijn ingeval van overtreding valt de statuten de ratio voor haar repressicf toczicht was vervallen - in dat geval was immers het, voorecht" van niet aansprakclijkheich niet meer aanwezig; zij nam versohillende benalingen in de wet op, watlanan do statuten zouden hebben te volkoen, in welk geval de Koninklijke Bewilliging zon mocten worden verleend; de redenen ran weigering zonden moeten worden medegedeold (ant. 37 lid 2), cuz. Jen een ging dit te ver, den ander nict ver genoog; de l'egeline, \%oodis deze ton slotte wet is geworden, hield het midden tussehen de voolstanders van algeheel regeeringstoezicht en de voonstinders van nitslniting van iedere benociing der Regeering; men bracht nog ter spu'ake de controle over te laten aan de rechterlijke macht, of zelts aan den P'ocureur Gencraal bij den Hoogen Ralad; doch dit laatste voorstel vond niet rolduenden weckliknk, en van de contrôle door den rechter vreesde men rechtsonzekerheid; te voren most worden vastgesteld en rool ieder moest controlecthalal zijn of de vennootschap al of niet bestond. al of nict an de wettelijke eischen had voldaan; dadrom achtte men de Rogeering de meest geschikte autoriteit om zullis te beoordcelen.

Tit het roorgande volgt dat de Procureur Generaal voor zijn meening omtrent de brteckenis ran artikel 50 terechl steun kon vinden in de gesehiedenis.

'Toch nam de lJooge Riad een ander' standpunt in.

De Ilooge Raad redencerde aldus: de Wot stelt drie vereisehten roor de tot standkoming eener Naanlooze Vennootschap, notarieele acte, Koninklijke Bewilliging en plaatsing van een vijfde gedeclte van het maatsehappelijk kapitaal.

Zoolang aan deze vereisehten niet voldaan is, bestaat de Naamlooze V'emnootschap niet en kan ook de rechter haar niet als bestanule anmerken. Controle ran de rechterlijke macht dus.

Maar -- cn $n$ u het komende ,male" is van groote beteokenis - de wet hecft geon tijdstip vastgestedd, warop alan den eisel van plaatsing van ecn vijfde gedeelte van het kalpital moct zijn voldam (de woorden ,.de ecrste oprigter's" in artikel 50 missen blijkbaal beteckonis); altikel 50 schept cen waalborg dat de plaatsing inderdand zal geschieden; doch in geval deze warborer niet dooltreffend blijkt to zijn geweest ( mislciling van- of onvoldoende onderzoek dool de Kjoon) komt de vennootschap door de koninkrijke Bewilliging op zich zelve niet tot stand, maar kim zij alsnog automatisch tot stand komen, wanneer matr eemnal een viffle gedeelte van het kapital in werkelijkheid is geplaatst.

Tit die beslissing volgele het roor het onderhavige geding dat het cerste rerweer van den a andeslhouder niet opging: het komt roor het bestaan der vemootschap en roor de mogelijkheid harer faillietverklaring niet ann op de plaatsing ten tijde dat de Koninklijke Bewilliging was verlecnd, maal ten tijde der faillietverklaring; en in dit geval was op dat tijdstip aan den eisch van artikel 50 voldaan.

Wanlom het un cigenlijk zoo is als de Hooge haad hecft beslist, kumnen wij niet zeggen; het arrest vermeldt het niet; uit de woorden van de wet ralt enrder het tegendeel af te leiklen, evenals uit de geschicdenis (zic boven) doch daarovel zwijgt het arrest dan ook geheel. Doch hoe dit zij, na het arıest staat vast, en is dus thans geldend recht, dat een naamlooze remootselap, ongeacht de verkiegen Konimklijke Bewilliging en oprichting bij notaricele acte, nict bestrat, zoolang niet in werkelijkheid ecn vijfle gedeclte van het kapitanl is geplaitst geworden, hetgeen bij geschil een punt van onder'zoek voor den rechiter moct opleveren.

Tenslotte nog en enkel woord orel het verdeze verweer van den bewusten aandeelhouder. 
Volgens den IIoogen Raal had de Nammlooze Vennootschap $n o g$ niet bestam op het vogenblik van de toetreding als aandechouder. Is dariran het gevolg, dat die verbintenis nu nietig is? Geenszins. De Ilooge Raad zegt het kort maar krachtig: het behoeft geen betoog dat een handeling, wettelijk vereischt voor het ontstem eener venootschap adn hal bestarn moet voorafgaan. Hen moct kapitál liunnen plaatsen voór het ontstaan; wanneer voldoende geplantst is ontstaat de vemnootschap, kan zij althans ontstaan; en wamneer dan cenmal, zij het ook op ecn later tijdstip dan hij de toetreding als aandeclhonder zelve, aan den eiseh van plaatsing is voldaan, is men verplicht ziju verbintenis van deelname in het kapitaal na te komen.

Wij meenen es de aandacht op te mocten vestigen, dat deze laatste beslissing bepaldelijk geldt voor de toctreding als aandeelhouder; bij andere verbintenissen jegens namlooze vennootschappen, bij welke cen vijfde gedeelte van het kapitaal nict of nog niet zou zijn geplaatst geldt dezelfde redeneering niet en zou dus cen andere beslissing moeten volgen. Daarin schuilt dus het practisch belang van het versehil van opvatting tusschen den l'rocureur Generaal en den Hoogen Raad.

Ilet beroep op het feit dat niet-voldalan zou zijn aan artikel 51 werd evencens verworpen. Velwondering wekt dit niet ,De beteckenis van dat artikel immer's is duidelijk geen andere, dan dat ecne naamlooze Vennootschap dic aan alle wettelijke eischen voldoet en die dus als rechtpersoon in het maatschappelijk verkeer zal optreden, desniettemin met hare werkaanheden sict zal mogen aanvangen, d.w.z. nicts ter verwezenlijking van halar doel zal mogen doen, zoolang niet $10 \%$ van halar geplaatst kapitaal in hare kas zal zijn gestort".

De Vennootschap bestakt dus wol, doch mag nog niet werken, kan nog geen verbintenissen aangaln ter verwezenlijking ran haar doel, dus in haar handel of bedrijf. Maar ook hier weer staat de verbintenis tot declname in het linpitaal daarbuiten. Wanneer de vennootschap eenmaal bestaat kan zij de nandeelhouder's tot de storting nookialien; is er voldoende gestort, dan kan zij cen aanvang nemen.

\section{Mr. A. E. .J. NYSINGH}

\section{ZEVENTIENDE VERBANDSTAG VAN DEN VERBAND DEU'TSCHER BÜCHERREVISOREN}

Van 27 tot 31 Mei j.l. Werd in keulen de zeventiende Velbandstag van den Verband Deutsoher Büchervevisoren gehouden. Ic openbare zittingen werden ook door enkcle Nederlandsche Accountants bijgewoond. Van een vall hen ontvingen wij het volgende verslag.

De eerste dagen van den Verbandstag wouden steeds ingenomen door huishoudelijke vergaderingen van hoofd- en afdeelingshesturen, dic uit alle afdeclingen warin het land verdeeld is. naar de elk jaar wisselende vergaderplaats komen.

$\mathrm{Y} \mathrm{oor}$ deze vergaderingen waren dit jaar de $27 \mathrm{c}$ en $28 \mathrm{e}$ Mei en de ochtend van 29 Hei anugewezen, zoodat het voor de bezuckers eerst op 29 Mei 's middags interessant werd.

Toor de openbal'e vergaderingen op '29 ch 30 Mei te houden was het volgende programma vastgesteld:

(Op 29 Mei. 1e. Toespraken vin den Voolzitter, van de autoriteiten en de gasten, dic beviende vereenigingen vertegenwoordigden.

2c. Die gesetæliche Regelung des Revisions- und Treuhandwesens in Dentschland", door Dr. jur. P'unl D. Schourp, Essen, lirl van den V.I.R.

3e. „Der Stant und dic Wirtschaft", door Geheimer Legations-Rat P'rof.' I)". Kurl Wiedenfeld, Leipzig.
Op 30 Mei :

1e. "Die Kurzfristige Wrfolgsrechmung", Referaat door 1)r. Rudolf Redeclier, Bremen, Lid V.D.B.

2c. "Grundsätzliches zur Konzernbewegung", Referaat door Dr. Fritz Sommer, Wiesbaden, Lid V.l).l?.

3c. ,. Die Auswirkungen der modelnen Buchfühn'ungsmethoden auf das Revisionswesen", Refelaat door Richurd Fischer, lueipzig, Lid V.IJ.l3.

()p den eersten dag hestond geen gelegenheid voor debat, wel na elk der referaten op den twecken dag.

Het zal den lezer opvallen, dat elk der bovengenoemde onderwerpen van belang is, ook voos den Nederlandschen Accomntant.

De wettelijke regeling is na langdurige eommissoriale besprekingen eindelijk in een rookanig stadium gekomen, dat cen wetsontwerp aanhangig is gemaakt. wanthoor de beëedigde en gcdiplomecrde Bücherrevisoren door inschrijving in ecn register, dat door de Handelskamer zal worden gehouden, gescheiden worden van de nict beëedigde en nict gediplomeerde Revisoren. Het beroep zal dus ook in Duitschland niet worden gesloten. De IIandelskamers zullen de examens afnemen, die aan de beëediging vooraf mocten gadn. De 'Treuhänder kmmen alleen in het register ingeschreven worden, wannecr ten minste cen der hestuurderen beëedigd en gediplonecrd Büchcrrevisor' is.

1)e referent sprak de verwachting uit, dat himnen nict te langen tijd dit wetsontwerp wet zou worden.

Van bijzondele belangrijkheid was de tweede roordracht, dic van Prof. Wiedenfeld, die met wan redenaal'stalent en groote kemis van het door hem behandelde onderwerp, zijn gehoor cen paar uur bocide. Spr. zette, na een inleiling over het lang\%almethand toenemende optreden van den Staat als leider van bedrijfshuishoudingen, niteen. hoe door de werking van de noodzakelijkheid voor den ambtenala om steeds het gevoelen van de hoogere instantic te radplegen, voor den Staat als bedrijfslcider veclal de gunstige gelegenheid on van marktvelanderingen te profiteeren, voorbij gaat. Dat is dan ook de reden, walarom do Staat alleen in clie bedrijuen met gumstig gevolg als leider kan optreden, waar re noolzakelijkheid van telkens ingrijpen niet of in mindere mate bestaat. Spr. schetste de pogingen om dit te verbeteren koor het opriehten van gemengde naamlocze vennootshappen c.d., en oogstte cen luid applaus, toen hij na een grondige behandeling daatran zijn lede cindigde.

Het zal ongetwijfcld leerzam zijn deze jede later gedrukt vool' zich te hebhen.

$\mathrm{Na}$ olk van de reforaten, dic den volgenden morgen gelezen werden, ontspon zich een levendig debat, warbij bleck, dat het nut van de Resultaat-overzichten op korten termijn, hetwelk de referent trachtte aan te toonen, dool cen aantal leden werd ontkend, vooral op grond daarvan, dat in zulk een korte termijn in bijna geen enkele onderneming de ontrangsten voortvlocien uit de in die periole gemalkte knsten. Dezo klebaters achitten daarom zulke herckeningen ondoelmatig. Door anderc werd het onjuiste van de\% beschomwing. althans voor cen groot alantal ondernemingen, aangetoond.

De tweede referent toonde aan, dat de Konzelnhlyeging niet als een algemeen grneesmiddel roor de Dnitsche zwakke hedrijfshuishouding kan worden anvandel. Al ziju enkele Conrerns ongetwịfeld nuttigrewest, van do klcine onderneming verwachtte hij voor het herstel van Duitschland het meeste heil. Eigenlijk veclal op te gronden den vorigen dag ook door prof. Tiedenfeld am gevoerd.

It invloed van modernen bockhoudmethoden (doorschrijfsystemen, met of zonder hulp ran bockhoudmachines) op ons beroep, werd door den derden spreker .,eingehend" behandeld. IIij bleek (wo zouden hịna zeggen: , ,natumrlijk") een groot voorstander van boekhondmachines es arbeidbesparende me- 